\title{
Comparative Study on Polyamide 6 Toughness using Multiple Melt-Kneading Techniques
}

\author{
Akira Ishigami, Takuya Konno, Takashi Kurose, Shotaro Nishitsuji, Masaru Ishikawa and Hiroshi Ito* \\ Graduate School of Organic Materials Science, Yamagata University, Japan
}

Submission: July 6, 2018; Published: July 20, 2018

*Corresponding author: Hiroshi Ito, Graduate School of Organic Materials Science, Yamagata University, Japan, Tel/Fax: +81-238-26-3081;

Email: ihiroshi@yz.yamagata-u.ac.jp

\begin{abstract}
In the present work, we tried to toughen polyamide 6 (PA6) by blending a small amount of low molecular-weight polyethylene (LMWPE). We obtained the PA6/LMWPE blends with different morphologies using multiple melt-kneading methods such as the uniaxial melt-kneading, the eight-axial screw melt-kneading, and the high shearing method. As a result, it was elucidated that the LMWPE was homogeneously and finely dispersed by using the eight-axial melt-kneading method. On the other hand, we found that for high shearing method the LMWPE was finely dispersed to a degree close to the compatible system. The result of the three-point bending test showed that the PA6 was brittle fractured, but it changed to ductile fracture when a small amount of LMWPE was blended. Also, the fracture displacement was extensively improved. The results of the comparison by the melt-kneading methods revealed that the toughness of the PA6 was improved even by adding a small amount of LMWPE (about 2\%) when they were blended using the eight-axial screw melt-kneading machine. The cross-sectional observation in the bending test showed that voids were produced from the LMWPE. We elucidated that the production of voids was induced with low stress by adding fragile LMWPE, resulting in the improvement of the bending toughness. Moreover, we found that the LMWPE needs to be finely dispersed with an appropriate particle size in order to exhibit ductile properties.
\end{abstract}

Keywords: Polymer blend; Higher order structure; Kneading extruder; High-shear rotational processing; High speed impact test

Abbrevations: PA6: Polyamide 6; LMWPE: Low Molecular-Weight Polyethylene; TM: Melting Point; TG: Glass Transition Temperature; MFR: Melt Flow Rate; MW: Molecular Weight; HSP: High-Shear Process Kneader; OSE : Octa Screw Kneading Extruder

\section{Introduction}

In recent years, due to the rise in environmental consciousness, weight reduction aimed at reducing the fuel consumption of automobiles is proceeding. Under these circumstances, the proportion of using light polymer in automobiles is increasing. However, extremely high mechanical properties are required for materials loaded in automobiles. For that reason, the number of cases has been increasing where a single type of polymer material cannot meet requirements in automobiles. One of the methods to solve this problem is to use polymer blend, a mixture of different kinds of polymer materials. Up to now, the research and development on polymer blend method have been extensively conducted as a method that exhibits various properties and functions. As a result, many polymer alloy materials with various characteristics have been proposed [1,2]. In particular, for polymer materials showing brittle fracture behavior, it is tried to change them to be ductile by blending elastomer and gum. However, with these methods, the rigidity of the polymer materials is generally reduced while increasing ductility $[3,4]$.
A crystalline polymer, polyamide 6 (PA6), is an engineering plastic that has extremely high mechanical property because of the strong molecular-molecular interaction of hydrogen bonds in amide group. Although PA6 has strong rigidity, it causes brittle fracture when imposed with a large displacement. Hence it is very important to change the property of PA6 to be ductile while maintaining its high rigidity [5].

In the present study, we tried to improve the toughness of PA6 by blending a small amount of low molecular-weight polyethylene (LMWPE). The purpose of the work is to clarify the relation between the inner structure and the mechanical property of the polymer blends with different morphologies produced by three different kinds of melt-kneading methods.

\section{Experimental Part}

\section{Samples}

PA6 (T802, Toyobo Co., Ltd.) was used as the matrix resin. The glass transition temperature (Tg) and the melting point 
(Tm) of PA6 were $50{ }^{\circ} \mathrm{C}$ and $218^{\circ} \mathrm{C}$, respectively. The melt flow rate (MFR) was $26 \mathrm{~g} / 10 \mathrm{~min}$ at $230{ }^{\circ} \mathrm{C}$. As a modifier of PA6, LMWPE (Hi wax 1105A, Mitsubishi Chemical Co.) was used. The LMWPE was denatured by maleic anhydride. The Tg was 104 ${ }^{\circ} \mathrm{C}$, and the average molecular weight $(\mathrm{Mw})$ of the LMWPE was 1,900. The molded film of LMWPE is an extremely brittle and low-strength material exhibiting a tensile strength of $1.4 \mathrm{MPa}$ and a breaking strain of 0.006 in a tensile test. The blend ratio of the samples were PA6/LMWPE=98:2 and 95:5 wt\%, and the kneading temperature was $250^{\circ} \mathrm{C}$.

\section{Melt-kneading methods}

The blend ratio, the details of the melt-kneading machines, and the kneading conditions for the present samples are shown in Table 1. The melt-kneading machines used were Single screw extruder (SSE) (CER40, Hoshi Plastic Co., Ltd.), Octa screw kneading extruder (OSE) (Technobell Co., Ltd.), and High-shear process kneader (HSP) (Niigata Machine Techno CO., Ltd). The OSE was used for low-shear kneading. Therefore, it is expected that we obtain the products with relatively large domain diameter. The OSE is a machine where all eight screws engage and rotate in the same direction. Since the resin stays among eight screws in the OSE, the long-time kneading is possible compared with the SSE. The HSP is a batch-type kneading machine and has a special screw with a small hole in the center (return hole). Hence, it is possible to knead a certain amount of resin at arbitrary rotation speed and time [6-9].

Table 1: Screw composition, kneading conditions of kneader and blend ratio.

\begin{tabular}{|c|c|c|c|}
\hline Kneader & $\begin{array}{c}\text { Screw } \\
\text { Configuration }\end{array}$ & $\begin{array}{l}\text { Screw Rotation } \\
\text { Speed }\left(\mathrm{min}^{-1}\right)\end{array}$ & $\begin{array}{l}\text { Kneading Time } \\
\text { (s) }\end{array}$ \\
\hline SSE & $\begin{array}{c}\mathrm{L} / \mathrm{D}=23 \\
(\mathrm{D}=35 \mathrm{~mm})\end{array}$ & 20 & 60 \\
\hline OSE & $\begin{array}{c}\mathrm{L} / \mathrm{D}=45 \\
(\mathrm{D}=15 \mathrm{~mm})\end{array}$ & 100 & 150 \\
\hline HSP & $(\mathrm{D}=28 \mathrm{~mm})$ & 2000 & 10 \\
\hline
\end{tabular}

The samples after kneading were pelletized, and then molded to three-point bending test pieces and flat plate test pieces using the injection molding machine.

\section{SEM observation}

The samples after kneading were frozen and fractured in liquid nitrogen, and the fracture surface was observed by a scanning electron microscopy (SEM).

\section{Mechanical properties and observation of plastic deformation region}

Three-point bending tests were conducted for specimens with notches. The Poisson contraction at the tip of the notch is suppressed due to the constraint of the distortion. Hence the pure uniaxial stretching test becomes possible. This test method is known to be effective for the evaluation of toughness (ductile or brittle) for polymer blend materials [10]. As additional experiments, the bending test was stopped at the displacement just before the fracture or at the maximum displacement (10 mm), and the sample was fixed by embedding with epoxy resin. The plane of the sample perpendicular to the tip of the notch was then scraped to $20 \mu \mathrm{m}$ thick thin film using a microtome. The void-producing region in the plane was observed with a polarization microscope.

\section{Impact resistance evaluation}

For evaluating the impact strength at the time of rapid deformation, a high-speed impact test (punching) was conducted. The sample molded to a plane shape was punched by a test rod of $10 \mathrm{~mm}$ diameter, and the stress was measured. The speed of the impact test was $10 \mathrm{~m} \cdot \mathrm{s}^{-1}$.

\section{Results and Discussion}

\section{Morphology observation}

Figure 1 shows the cross-sectional SEM images for PA6/ LMWPE kneaded by SSE (a) and OSE (b). For the SSE-kneaded sample, LMWPE aggregates with a maximum particle size of $3 \mu \mathrm{m}$ were observed. The size of the aggregates was not homogeneous. For the OSE-kneaded sample, we confirmed the LMWPE aggregates with a particle size from $1 \mu \mathrm{m}$ to $2 \mu \mathrm{m}$. The size of the aggregates was relatively homogeneous compared with that of the SSE-kneaded sample. For the HSP-kneaded sample, LMWPE aggregates were not observed. The reason would be that the LMWPE was extremely finely dispersed in this case.
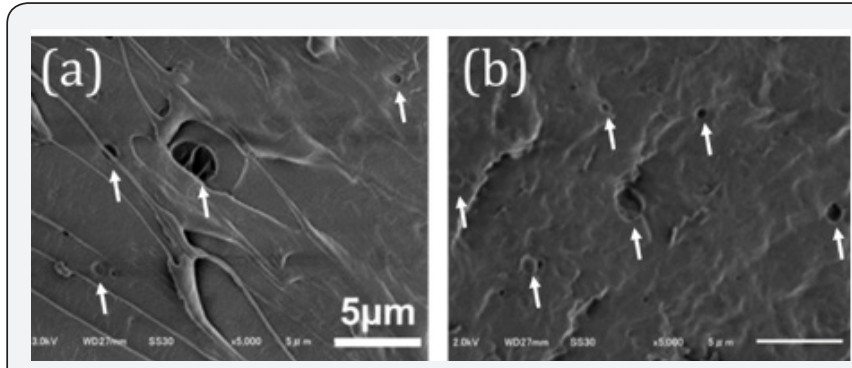

Figure 1: SEM image of the cross-section for after kneaded (a) SSE and (b) OSE.

\section{Three point bending test and observation of plastic deformation region}

Figure 2 displays the results of the three-point bending test for pure PA6 and PA6/LMWPE blends produced by respective kneading methods. Only OSE kneaded-samples were prepared with LMWPE addition amount of 2 and $5 \mathrm{wt} \%$. For the pure PA6, SSE-kneaded sample, and HPS-kneaded sample, they were finally brittle fractured. In particular, for the HSP-kneaded blend, the fracture behavior was same as that of the pure PA6, thus the effect of the LMWPE blending could not be confirmed. On the other hand, the OSE-kneaded sample showed plastic deformation, and it was not fractured even at the maximum displacement $(10 \mathrm{~mm})$ resulting in the general yield. The OSE kneaded sample (LMWPE: 5wt\%) showed better breaking elongation than the system in which LMWPE(added 2wt\%), but the maximum bending strength greatly decreased. This result seems to be due to excessive addition of brittle LMWPE. 
Figure 3 presents the polarization microscope image of the plastic deformation region produced at the tip of the notch in the bending test. For the pure PA6 (a), voids were not produced even at $3.2 \mathrm{~mm}$ deformation, just before the fracture. While for SSE-kneaded blend (b), the plastic deformation region originating from the voids formation was confirmed for the sample just before the fracture (displacement: $6 \mathrm{~mm}$ ). In this case, the blending of LMWPE induced the void formation, and the Poisson contraction among the voids became possible, which led to the ductile behavior of the sample compared with the pure PA6. However, the stress was locally concentrated because of the inhomogeneous size of the dispersed LMWPE. Therefore, it is considered that the sample finally resulted in the brittle fracture.

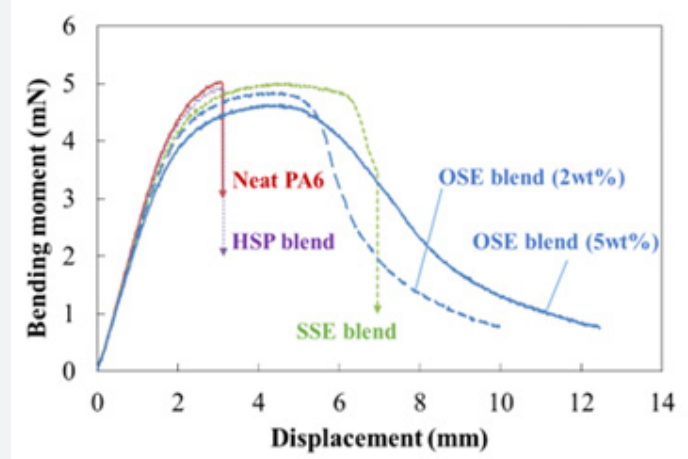

Figure 2: Bending moment-Displacement curves of three point bending test.

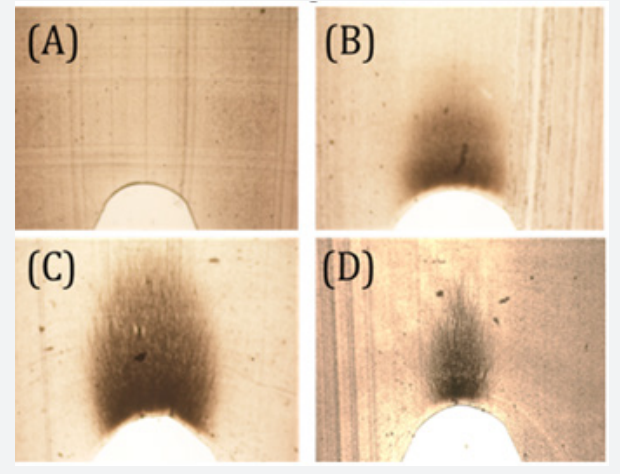

Figure 3: Polarizing photograph of plastic deformation region (a) Neat PA6, (b) SSE blend, (c) OSE blend, (d) HSP blend.

For the OSE-kneaded sample (c), we confirmed the plastic deformation regions that are wider than those for the SSEkneaded one at the same displacement $(6 \mathrm{~mm})$. Compared with the SSE-kneaded sample, the OSE-kneaded one exhibited morphology where the size of the LMWPE aggregates was small and homogeneous. Therefore, the distance among the LMWPE aggregates was homogeneous, so the sample was homogeneously deformed due to the dispersion of the stress. As a result, it is considered that the sample resulted in the general yield without the brittle fracture even at the maximum displacement.

For the HSP-kneaded sample (d), we observed a fine plastic deformation region at the displacement $(3.2 \mathrm{~mm})$, just before the fracture. By the high shearing kneading, the LMWPE showed the dispersion condition that is close to the homogeneous compatibility system. As a result, voids expansion did not proceed because the size of the produced voids was extremely small. Thus, the stress constraint was not relaxed because the Poisson contraction was not sufficient. This would be the reason that the HSP-kneaded sample finally resulted in the brittle fracture. Based on the above results, we controlled fragile LMWPE to exhibit fine (about $1 \mu \mathrm{m}$ size) and homogeneous higher-order structure. By doing so, the void formation was induced, and the stress was relaxed. As a result, we succeeded in improving the toughness of PA6. On the other hand, the HSP-knead blended sample with excessively finely dispersed LMWPE did not have a higher-order structure. We consider that the blending of LMWPE did not lead to improve the toughness of PA6 in this case because the stress relaxation function did not work.

\section{High-speed impact test}

Figure 4 shows the load-displacement curve in the highspeed impact test at $10 \mathrm{~m} . \mathrm{s}-1$. At this speed, both the PA6 and the HSP-kneaded samples were brittle fractured. The reason is that in both samples the cracks were developed because the stress was not relaxed in the deformation at the high speed. On the other hand, the SSE- and OSE-kneaded samples showed ductile fracture. For these samples, the LMWPE that is easy to be fractured existed as domains with $1-3 \mu \mathrm{m}$ diameter. The stress relaxation effect expressed even at high speed of $10 \mathrm{~m} \cdot \mathrm{s}^{-1}$ because the LMWPE became the origin of voids. Based on these results, we succeeded in leading the SSE- and OSE-kneaded blends to the ductile fracture. On the other hand, the effect of the stress relaxation effect in the HSP-kneaded sample that has extremely fine dispersed structure of the LMWPE was not sufficient. We consider this is the reason why the HSP-kneaded sample led to the brittle fracture.

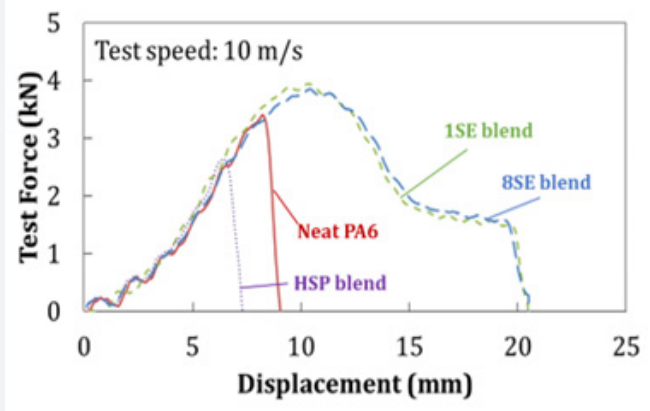

Figure 4: Result of high-speed impact test with test speed $10 \mathrm{~m} / \mathrm{s}$.

\section{Conclusion}

In the present work, we tried to toughen PA6 by blending a small amount of LMWPE. We obtained the PA6/LMWPE blends with different morphologies using multiple melt-kneading methods such as the uniaxial melt-kneading, the eight-axial screw melt-kneading, and the high shearing method. As a result, it was 
possible to lead to ductile fracture while maintaining rigidity by adding a small amount of LMWPE to PA6. Kneading by OSE was effective for finely dispersing LMWPE and equalizing dispersed particle size, and the properties of the blended material were also the most stable. This result seems to be because Poisson contraction was possible even at high speed deformation, and PA6 could lead to ductile fracture, since LMWPE which breaks easily is the starting point of void formation. However, when LMWPE was dispersed in a region close to the nano order and homogeneous system, the effect of adding LMWPE did not appear. It has been found that it was important to form a higher order structure having an island phase size larger than a certain level for toughening by polymer blending.

\section{Acknowledgement}

This research was partially funded by Impulsing Paradigm Change Through disruptive Technologies (ImPACT) Program of Council for Science, Technology and Innovation (Cabinet Office, Government of Japan).

\section{References}

1. Je Kyum Lee, Chang Dae Han (2000) Evolution of polymer blend morphology during compounding in a twin-screw extruder. Polymer 41(5): 1799-1815.

2. Kawada J, Kitou M, Mouri M, Kato Y, Katagiri Y, et al. (2017) Super Impact Absorbing Bio-alloys from Inedible Plants. Green Chem 19: 4503-4508.

This work is licensed under Creative Commons Attribution 4.0 License DOI: 10.19080/AJOP.2018.01.555563
3. Huang J J, Keskkula H, Paul D R (2004) Rubber toughening of an amorphous polyamide by functionalized SEBS copolymers: morphology and Izod impact behavior. Polymer 45(12): 4203-4215.

4. Okamoto Y, Miyagi H, Kakugo M, Takahashi K (1991) Impact Improvement Mechanism of HIPS with Bimodal Distribution of Rubber Particle Size. Macromolecules 24(20): 5639-5644.

5. Heino M, Hietaoja P, Seppälä J, Harmia T, Friedrich K (1997) Studies on fracture behavior of tough PA6/PP blends. J App Polym Sci 66(12): 2209-2220.

6. Shimizu H, Li Y, Kaito A, Sano H (2005) Formation of Nanostructured PVDF/PA11 Blends Using High-Shear Processing. Macromolecules 38(19): 7880-7883.

7. Y Li, H Shimizu (2011) Fabrication of nanostructured polycarbonate/ poly(methyl methacrylate) blends with improved optical and mechanical properties by high-shear processing. Polym Eng Sci 51(7): 1437-1445.

8. Ishigami A, Kodama Y, Suenaga H, Inoue T, Ito H (2016) Mechanical Properties and Structure of Novel Polymer Blends and Composites Fabricated by Reactive and High-shear Rotational Processing. Energy Procedia 89: 30-37.

9. Ishigami A, Kodama Y, Wagatsuma T, Ito H (2017) Evaluation of Structures and Morphologies of Recycled PC/PET Blends Fabricated by High-Shear Kneading Processing. Int Polym Proce 32(5): 568-573.

10. Ishikawa M, Ushui K, Hatada K (1996) Stability of plastic deformation in polyolefins. Polymer 37(9): 1601-1605.

\section{Your next submission with Juniper Publishers will reach you the below assets}

- Quality Editorial service

- Swift Peer Review

- Reprints availability

- E-prints Service

- Manuscript Podcast for convenient understanding

- Global attainment for your research

- Manuscript accessibility in different formats

( Pdf, E-pub, Full Text, Audio)

- Unceasing customer service

Track the below URL for one-step submission

https://juniperpublishers.com/online-submission.php 